\title{
Personalized ATMs: Improve ATMs Usability
}

\author{
Armin Kamfiroozie and Marzieh Ahmadzadeh \\ IT Department, e-Learning faculty - Shiraz University of Technology, Iran \\ armin.kamfiroozie@gmail.com, ahmadzadehesutech.ac.ir
}

\begin{abstract}
Using customization in products and services is one of the important methods for obtaining customers' satisfaction. In this paper, the personalized ATMs have been introduced which as one of the objectives, using personalization and customization methods, improve the efficiency and simplicity of usage of the ATMs and enable the users to benefit from the machine commensurate with their needs. In this system, based on general information about users and the records of customers' activities in CRM system, the information and screens are displayed which are predicted to be most applicable for the customers. This system is able to provide services based on users' abilities in order to enable all the customers to acquire their needed services from the system in the shortest time duration and highest efficiency.
\end{abstract}

Keywords: ATM, Auto Teller Machine, Customization, Personalization, HCI.

\section{Introduction}

It passes few decades from now when the first ATM appeared whose duty was to receive bills and deposit into customers' accounts and after a while, it could do all banking operation and now it performs other services even further than financial operation and its services are added unremittingly. Self-Service systems' family is being developed and various systems are included to this broad family. ATMs and interactive kiosks are the most famous members of them. Kiosks' applications have their own features and diversities, like doing financial, educational, entertainment, business, and communicative services. They also have different types in terms of appearance from a simple photo kiosk to financial and internet kiosks. Financial kiosks have usually a mouse, keypad, touch screens, card reader, etc., and services like getting news and information, filling out forms and operations like this are carried out by them. However, prevalent interactive kiosks have not capability of cash dispense/deposit and this task is on ATMs; ATMs generally have a monitor, card reader, printers, cash dispense/deposit modules, keypad and sometimes barcode scanner and sound system, etc. A standard and simple form of ATMs has made the use of them easy and there is no need to work with multipart and complicated systems like interactive kiosks [1], [2]. We apply existing ATMs for increasing the variety of services and personalizing them. Of course, some of the financial kiosks are also offering receiving and dispensing systems now that have turned them into very expensive and well-equipped systems, but they are rare. 


\section{Motivation}

By adding each new service on the ATM, new menus should also be available on the device. Most of the ATMs have only four buttons on the right and four ones on the left of the screen so the number of menus in each screen is limited. Crowded lines, long process of doing an operation, complexity and increase of menus and difficult use of this device for low illiterate or disabled people, are problems we will face with the increase of services on current ATMs, [3], [4]. For many reasons, all presentable services in kiosks are not suitable to be carried out via ATMs. ATM is a public and widely used device, and time period of use is limited for each person. Actually services must be in a way that the user only needs minimum inputs, and if it is indented a purchase is made, that goods or service should be prepared and available as a prepayment in advance and not have a great variety either. These services should also be usable by special people like the blinds, illiterates, foreign and deaf people. But all of these services are not always applied for all walks of life, and it is not necessary to display all of them in each use of the ATM [3], [4].

\section{Customized ATMs}

Nowadays, the customization in management of relations with customers has turned into one of the most key factors in manufacturing and service companies and the businesses which are more adaptable with their customers, are more successful [5]. This approach is available in CRM system of banks through processing clients' activities [1], [6]. Providing services on ATMs and changing the screens based on the clients' needs are conducted in two ways; personalization and customization.

\subsection{Customization vs. Personalization}

The personalization is carried out in contents and data levels and requires analysis and processing of users' data and activities history. The users will not need to deal with designing and selecting their favorite menus. Thus, there must be various and appropriate data and available knowledge about the users. While in customization this action is done manually by the users in such a way that the users select the information which they are willing to be displayed and also they determine how the order and method of manifestation would be. The Profile is used in this way. Since one of the purposes of personalization is reducing the user's performed operation and speeding up the transaction and on the contrary, in customization, the user is required to be active and play a role in creating the desired situation and structure, therefore some sort of contradiction occurs [5]. An inactive user who likes use his favorite menus are not usually willing to spend time creating the respective profile.

Consequently, regarding the objective of this system, customization is barely used and practically the focus in the ATMs is on personalization. The bank cards are used to withdraw money from ATMs, utilized in banks, using in mobile banking operations, shopping from stores and doing online purchases [1], [2]. The bank network is suitably connected to other even in whole the world and wherever you use your card, the transaction record will be kept by your bank [2], [6]. 


\subsection{Customization and Personalization in ATMs}

In personalized ATMs all the clients' records are stored in CRM system and will retrieve from it and other related databases. These data are collected and updated in several stages: at the time of opening the account, while the account is used for mentioned purposes, or according to customers demand at the time of using the card. These data include personal information and also the records of purchases and performed transactions including time, place or the websites where the purchases have been done, list of the people who you have had financial relations and other services you have taken from the machine such as the type of the withdrawn sums, the purchased tickets, payment invoices and so on [5], [6].

By analyzing these data and personal information of customers, the screens and menus can be predicted and displayed based on the clients' needs. In this method the customers must enter their PIN after inserting the card. The PIN screen is usually identical for all users with any physical and social conditions [7]. The PIN code and card number are then sent to center in the first connection and if it authorized, based on the card number and other processed information the ATM do proper action. In a more advanced design, users can assign two passwords to their account and based on entered password the way of personalization would be different.

For instance a person, suffering from optical problems, following inserting his/her card will observe a screen in which colors and other fonts have been designed for the optical disordered people and the audio system could be activated, or for example for less educated people following entering the PIN code, some screen with graphical menus is displayed and the audio system of machine is also activated [8] (Figure 1).
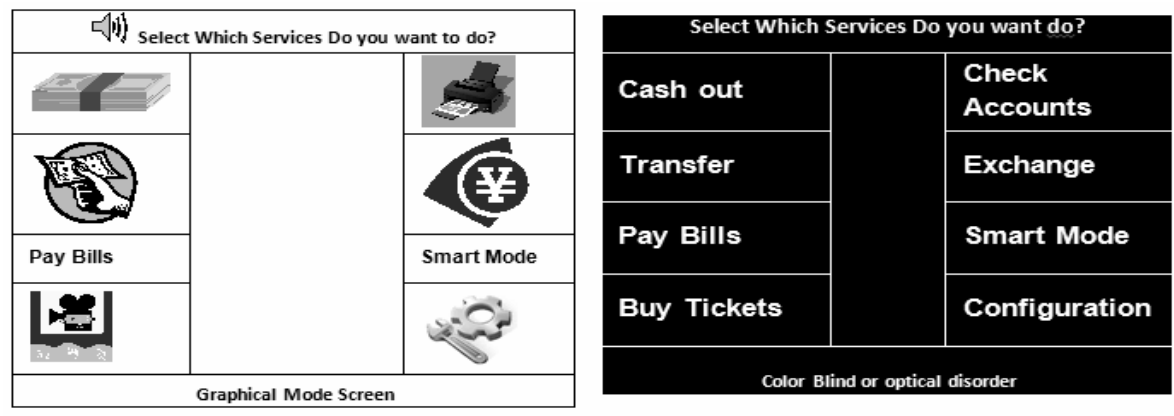

Fig. 1. Sample screen on personalized ATM for illiterate or optical disordered people

In another example an ordinary person, after entering PIN code, observes a screen in which one of assigned options is purchasing the ticket of the matches or concert which are to be held on that week, this information is based on the customers' records that indicate interest in participation in sport matches or concerts and ticket purchasing. This method of reminding and suggesting can be also applied for recalling the payment of installments and bills or introducing newly added services. It must be remembered that services in the form of previously prepared packages for purchases (such as ticket purchasing and charging telephone) are readily available for sale in ATMs. In personalized ATMs, all the services are available but the order and priority and the way of offering services and representation are different. 


\section{Implementation Feasibility}

The processing of user's activity and prediction and creation of personalized pages for client is carried out by the software installed on the server and connected to the CRM system of the organization and there is no need to change the current cards or ATMS to approach mentioned goals. All the screens and menus could be saved in offline mode in the ATMs. The menu combinations and the order of screen can be transmitted between machine and datacenter in the form of encoded data having very low bandwidth usage and can be stored in some bytes (Fig. 2). The interpretation of codes is done in the installed software of the ATM.

Some of users, while using the ATM, do not like changes in the appearance of the menu of machine or they are willing to impose the changes themselves. In this case, customization and profiles must be used instead of personalization. The encoding manner and saving of the screens arrangements can be done as before.

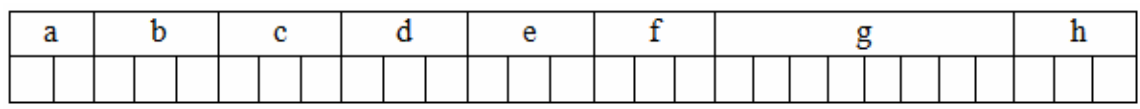

Fig. 2. Sample byte set for storing personalization information

a) The way of system representation: Default - Personalized - Profile Based.

b) The user's selected language: Common languages or graphical Mode

c) User's physical and corporal condition: Healthy, Optical Disordered, Deaf, etc.,

d) Type of currency to be used

e,f,g) Custom Screen Contents.

h) Reserved for unpredictable needs.

There could be an option like "Configuration" in the "other services" menu through which the card and personalization settings can be manipulated. These settings are conducted in the form of "Wizard" and the user is able to select the type of personalization service through it. In more advanced states, a combination of these two methods can be applied. In this mode, the menus that generated by analyzing customer history are more like recommendation. The generated code for creating the screens and customized menus can be saved and used in two ways:

- Saving in offline mode on the customer's card

- Receiving in online mode from the center

Saving in offline mode results in reduction in connection to center and therefore this mode is more appropriate at the time of high network traffic and server overloads. In this way, the customers see their own personalized page at the moment of inserting the cards. In this circumstance, it is needed to read and write on the cart every time and it's not very suitable. In the second method, the analyzed data in the bank CRM system are up-to-date and the relevant personalized code of customer can be obtained using the last changes and executed transactions by considering other available data. In this method, the data are sent to the center as soon as entering the PIN and if it authorized, operation with personalized ATM will continue (Figure 3). 


\begin{tabular}{|c|c|c|c|c|c|c|c|c|c|}
\hline \multicolumn{2}{|c|}{ Enter Your PIN } & \multicolumn{2}{|c|}{ Choose Language } & \multicolumn{2}{|c|}{ Select Service } & \multicolumn{2}{|c|}{ Cash Amount } & \multicolumn{2}{|c|}{ Which Account? } \\
\hline & & English & Persian & $\begin{array}{l}\text { Cash } \\
\text { Withdrawal }\end{array}$ & PIN Change & $10 \$$ & $150 \$$ & & \begin{tabular}{l|l}
$0300 x x x$ \\
\end{tabular} \\
\hline & & French & Arabic & $\begin{array}{l}\text { Balance } \\
\text { Inquiry }\end{array}$ & \begin{tabular}{|l|} 
Mini \\
Statement
\end{tabular} & $20 \$$ & $200 \$$ & & $0100 \mathrm{YYY}$ \\
\hline & & Arabic & Spanish & Transfer & Card Charge & $50 \$$ & $300 \$$ & & $0200 Z z Z$ \\
\hline & & Portuguese & & Bill Payment & Other & $100 \$$ & Custom & & \\
\hline \multicolumn{2}{|c|}{ 1st Screen After Inserting Cart } & \multicolumn{2}{|c|}{ 2nd Screen } & \multicolumn{2}{|c|}{ 3rd Screen } & \multicolumn{2}{|c|}{ 4th screen } & \multicolumn{2}{|r|}{ 5th Screen } \\
\hline \multicolumn{2}{|c|}{ Receipt? } & \multirow{6}{*}{\multicolumn{2}{|c|}{\begin{tabular}{|l|} 
Making connection, \\
authorizing, available \\
fund and ... is checked \\
in the last step. If one of \\
them fails, all steps \\
should be done again.
\end{tabular}}} & & \multirow{5}{*}{\multicolumn{2}{|c|}{\begin{tabular}{|l|} 
Making connection, \\
authorizing, available fund \\
and personalization data \\
will be checked at first and \\
everything will be shown \\
based on this information.
\end{tabular}}} & \multicolumn{3}{|c|}{ Select Service (English) } \\
\hline & & & & & & & \multicolumn{2}{|c|}{$\underset{\text { Receipt }}{2005(02002)^{+}}$} & $\begin{array}{l}\text { Pay } 127 \$ \text { Gas Bill } \\
\text { (0100YYY) }\end{array}$ \\
\hline \multirow[t]{3}{*}{ No Receipt } & \multirow[t]{3}{*}{ Receipt } & & & & & & \multicolumn{2}{|c|}{\begin{tabular}{|l|} 
Charge MTN 10\$ \\
From 0300XXX \\
\end{tabular}} & $\begin{array}{l}\text { Donate } 3 \$ \text { to } A B C \\
\text { orphanage }\end{array}$ \\
\hline & & & & $\begin{array}{l}\text { Person } \\
\text { ATM }\end{array}$ & & & \multicolumn{2}{|c|}{ Buy 20 \$ Lottery } & $\begin{array}{l}\text { Print 0100YYY } \\
\text { Details } \\
\end{array}$ \\
\hline & & & & & & & $\begin{array}{r}10 \$(02 \\
\text { No R }\end{array}$ & & Other Services \\
\hline \multicolumn{2}{|c|}{ 6th screen } & & & & \multicolumn{2}{|c|}{ 1st step entering PIN } & \multicolumn{3}{|c|}{ 2nd screen - Personalized Screen } \\
\hline
\end{tabular}

Fig. 3. Sample comparison between doing an operation in current ATM vs. personalized ATM

\section{Conclusion}

In this paper a model was presented for personalizing ATMs which is able to provide more services, moreover will recognize and help you to carry out your tasks more rapidly based on your needs. Improving the efficiency and usability of these devices is a result of personalizing screens and services [3]. These ATMs can offer purchases or services commensurate with your tastes and daily life. In this case you will find what you need quickly instead of memorizing the whole path of operation. They might talk and interact with you in an effective way [8]. Possibility to add efficient and purposive advertisements based on geographical or location of ATM leads the machine to be more profitable and compensate the costs that customers undergo [1], [6]. This model can also be used in Kiosks as another member of this family. As you previously had friendly relations with banks clerk and he was treating you differently compared to others, now this expectation will be fulfilled by machine clerks. They are kind of forthcoming Self-Service Machines which you can meet all you need.

\section{References}

1. First Data Corporation, http://www. firstdata.com

2. Automated Teller Machine business news, research, more, http: / / www . atmmarketplace.com

3. Yarlikas, S.: A New Automatic Teller Machine (ATM) Proposal through the Analysis of ATMs of Three Banks. In: Jacko, J.A. (ed.) HCII 2009. LNCS, vol. 5613, pp. 641-650. Springer, Heidelberg (2009)

4. Cremers, A.H.M., de Jong, J.G.M., van Balken, J.S.: User-Centered Design with Illiterate Persons: The Case of the ATM User Interface. In: Miesenberger, K., Klaus, J., Zagler, W., Karshmer, A. (eds.) ICCHP 2008. LNCS, vol. 5105, pp. 713-720. Springer, Heidelberg (2008)

5. Tseng, M.M., Piller, F.T. (eds.): The Customer Centric Enterprise: Advances in Mass Customization and Personalization, New York, Berlin, p. 168 illus (2003) 
6. Hosono, N., Gotanda, S., Inoue, H., Tomita, Y.: ATM Advertisement and Financial Preferences with Sensory Analysis. In: Jacko, J.A. (ed.) HCII 2007. LNCS, vol. 4553, pp. 42-47. Springer, Heidelberg (2007)

7. Moncur, W., Leplatre, G.: Pictures at the ATM: exploring the usability of multiple graphical passwords. In: Proceedings of the SIGCHI Conference on Human Factors in Computing Systems (CHI 2007), pp. 887-894. ACM, New York (2007)

8. Akatsu, H., Komatsubara, A.: Auditory and Visual Guidance for Reducing Cognitive Load. In: Kurosu, M. (ed.) HCD 2009. LNCS, vol. 5619, pp. 391-397. Springer, Heidelberg (2009) 